\title{
Compensation claims following anterior cruciate ligament injuries reported to the patient insurance company in Sweden in 2005-2014
}

\author{
Osama OMAR ${ }^{1}$, Dzan RIZVANOVIC ${ }^{2}$, Markus WALDÉN ${ }^{3}$, Karl ERIKSSON ${ }^{1}$, Björn BARENIUS ${ }^{1}$, \\ and Anders STÅLMAN 4
}

\begin{abstract}
${ }^{1}$ Department of Clinical Science and Education, Södersjukhuset, Karolinska Institutet, Stockholm; ${ }^{2}$ Department of Orthopaedics, Växjö Central Hospital, Region Kronoberg, and Department of Molecular Medicine and Surgery, Stockholm Sports Trauma Research Center, Karolinska Institutet, Stockholm; ${ }^{3}$ Unit of Community Medicine, Department of Health, Medicine and Caring Sciences, Linköping University, Sweden, and Department of Orthopaedics, Hässleholm-Kristianstad Hospitals, Hässleholm; ${ }^{4}$ Capio Artro Clinic, and Department of Molecular Medicine and Surgery, Stockholm Sports Trauma Research Center, Karolinska Institutet, Stockholm, Sweden

Correspondence: osama_omar@me.com

Submitted 2021-08-05. Accepted 2021-10-01.
\end{abstract}

Background and purpose - Patients in the Swedish healthcare system are insured against avoidable adverse events via Landstingens Ömsesidiga Försäkringsbolag (LÖF). We assessed the reasons for compensation claims reported to LÖF following an ACL injury.

Patients and methods - We searched the LÖF database for compensation claims related to ACL injuries reported in 2005-2014, and cross-matched claims with the Swedish National Knee Ligament Register. We then performed a review of the medical records.

Results - We identified 530 eligible claims in 20052014. $352(66 \%)$ claims were accepted by LÖF and 178 claims were rejected. Accepted claims corresponded to fewer than $1 \%$ of ACL surgeries performed in the same period. The most common reasons for an accepted claim were postoperative septic arthritis followed by suboptimal surgery and delay in diagnosis and treatment.

Interpretation - There are different reasons for accepting a compensation claim following an ACL injury, which represents different treatment errors that can be avoided.
According to the Swedish Patient Safety Act, healthcare personnel are obliged to inform patients about the opportunity to file a compensation claim if an avoidable patient injury occurs (1). The Mutual Insurance Company of Swedish County Councils (Landstingens Ömsesidiga Försäkringsbolag [LÖF]) handles patient claims in public healthcare in accordance with the Patient Injury Act (2).

The annual incidence of an ACL injury in Sweden is reported to be 78/100,000 (3). In Scandinavia, 34-38/100,000 undergo ACL reconstruction (ACLR) each year (4). Approximately $90 \%$ of ACLRs in Sweden are reported to the Swedish National Knee Ligament Register (SNKLR) (5).

An ACL injury can be followed by serious and sometimes avoidable complications (6). Claims accepted by the insurance authorities could be technical errors during surgery, iatrogenic nerve injuries, inferior diagnostics, and infections. A better understanding of the common treatment injuries that occur during treatment of ACL injuries can improve the care of these patients.

We assessed the reasons for and consequences of treatment errors and patient injuries found in compensation claims reported to LÖF following an ACL injury.

\section{Patients and methods}

Compensation claims are filed by patients and LÖF obtains full medical records from the treating physicians. The medical records are reviewed by medical consultants at LÖF.

LÖF rejects claims if the event was not avoidable, the symptoms are without a causal relationship with the event, or if the treatment injury is adjudged to be mild in relation to the illness 
or treatment given and should therefore be regarded as tolerable. If the claim is accepted, LÖF compensates for prolonged recovery times, for increased permanent disability, for unreimbursed medical expenses, and for income loss. The system is blame-free for healthcare providers and no records are shared with the regulatory authorities (7). Generally, around half of all the claims reported to LÖF are adjudged to be valid and eligible for compensation (8).

We studied patients with insurance claims submitted to LÖF between 2005 and 2014 and related to an ACL injury. Our aim was to include all ACL-related claims, regardless of choice of treatment. First, we searched LÖF's database for claims with ICD-10 codes related to knee ligament injuries, S83.5, S83.6, S83.7, or M23.5. We then made a crossmatch of the patients who underwent an ACL reconstruction and were registered in the Swedish National Knee Ligament Register from January 1, 2005 to December 31, 2014 with the LÖF's database to obtain the proportion of claims in relation to the number of ACLRs. Claims not related to an ACL injury were excluded.

The data was categorized into 2 groups: accepted or rejected claims. We studied the causes of claims in both groups and compared demographic data. For the group with accepted claims, we further studied the review and decisions made by LÖF, including any increase in recovery time, any increase in permanent disability, and the amount of economic compensation given.

The increase in recovery time is defined as the additional time required for recovery caused by the adverse event, apart from the time for recovery due to the ACL injury itself. Similarly, the increase in permanent disability is the disability due to the adverse event, apart from the expected disability caused by the ACL injury and the coherent associated injuries themselves. $0 \%$ disability corresponds to normal bodily function and $100 \%$ disability is considered to exist when no bodily function remains.

Accepted claims were divided into 7 subgroups: postoperative septic arthritis, suboptimal surgery, delay in diagnosis and treatment, nerve injuries, wounds and scars, compartment syndromes, and others (Figure 1).

\section{Data availability statement}

The study was based on data obtained upon request and subject to license restrictions from LÖF (the National Swedish Patient Insurance Company) and Xbase (the Swedish National ACL Register). The data supporting the findings of this study is included in the article.

\section{Ethics, funding, and potential conflicts of interest}

The study was conducted in accordance with the Declaration of Helsinki and approved by the Ethical Review Board, Karolinska Institutet, Sweden, 2016/47-31/5. Financial support was received from LÖF. AS, BB, and KE have been involved in LÖF as medical consultants. There are no other conflicts of interest.

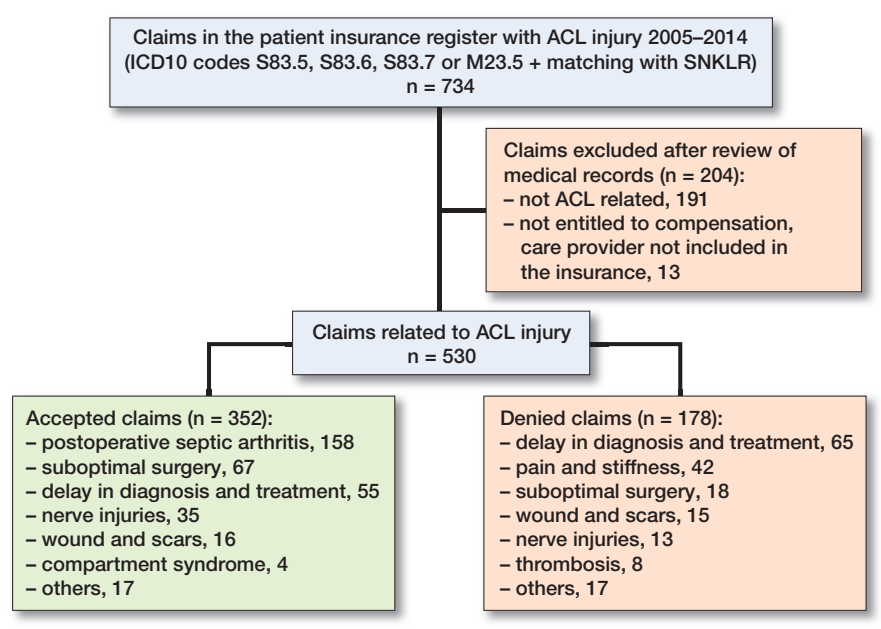

Figure 1. Flow chart of patients and methods

\section{Results}

Using the search criteria, we found 734 claims between 2005 and 2014. After a review of the medical records and the exclusion of non-ACL-related injuries and patients not entitled to compensation, e.g., due to the care provider not being included in the insurance, 530 eligible claims remained. Of these claims, $352(66 \%)$ were accepted after assessment by medical experts at LÖF (Figure 1). 342 of the accepted claims relate to patients who had undergone ACLR. The median age of the patients with accepted claims was 25 years and $43 \%$ were women. For comparison, during the period 2005-2014, 30,473 primary ACLRs and 2,046 revision ACLRs from a total of 83 clinics were registered in the SNKLR. The average age at surgery in the SNKLR is 28 years and $40 \%$ were women. Accordingly, accepted claims correspond to fewer than $1 \%$ of ACL surgeries performed. The median number of accepted claims each year between 2005 and 2014 was 35 (26-48).

The 3 most commonly accepted adverse events were postoperative septic arthritis $(\mathrm{n}=158)$, suboptimal surgery $(\mathrm{n}=$ $67)$, and delay in diagnosis and treatment $(n=55)$. There were 103 males and 55 females in the postoperative septic arthritis subgroup, but in the other subgroups sex was fairly evenly distributed. Of those claims that were rejected, the 3 main reasons for filing a claim were delay in diagnosis and treatment $(n=65)$, pain and stiffness $(n=42)$, and suboptimal surgery $(\mathrm{n}=18)$ (Figure 1).

Compensation claims regarding postoperative septic arthritis were always accepted. It is regarded by LÖF as a serious treatment injury resulting from intraoperative contamination that often leads to severe consequences.

8 claims regarding thrombosis were rejected after individual assessment ensuring no treatment errors were made and that treatment was in line with accepted medical practice.

Different results of the decisions made by LÖF were found for the subgroups of suboptimal surgery, delay in diagnosis 


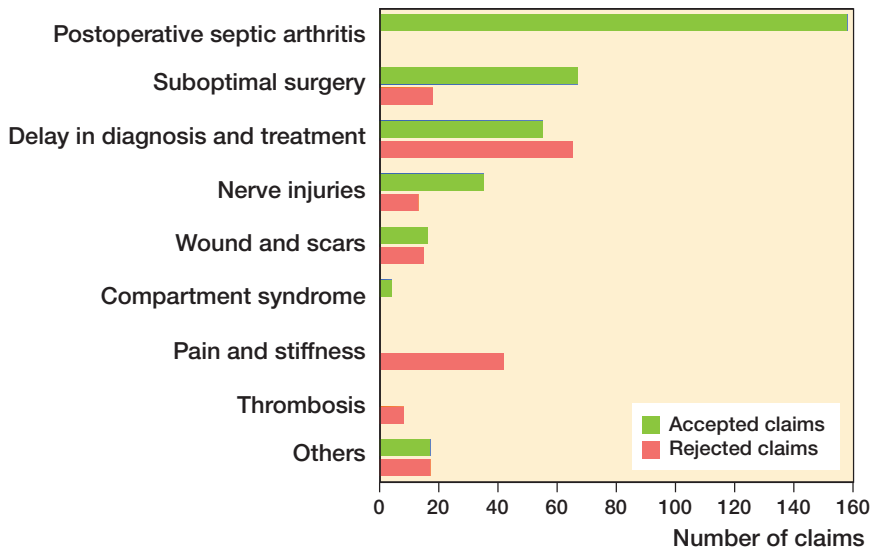

Figure 2. Number of accepted and rejected claims related to ACL injury in Sweden in 2005-2014 categorized according to cause.

and treatment, nerve injuries, wound and scars, and others (Figure 2).

For the subgroup of suboptimal surgery, the most commonly accepted claim was incorrect tunnel placement $(\mathrm{n}=$ 24). However, the claims were rejected if the graft placement was considered to be in line with consensus at the time of surgery. Another commonly accepted claim was failed fixation, such as problems with malpositioned interference screws or cortical buttons $(n=24)$. Problems with harvesting and management of grafts $(n=9)$ were compensated when the graft was dropped or damaged and the surgeon had to harvest a new graft, which resulted in an additional harvest site and increased morbidity. Iatrogenic patellar fractures $(n=5)$ were compensated in 3 patients with patellar tendon grafts and 2 patients with quadriceps tendon grafts. 2 claims were compensated due to iatrogenic cartilage damage.

For the category of delay in diagnosis, the most commonly accepted claim was a missed ACL injury where the patient had persistent subjective instability without being given the correct information and treatment, resulting in associated meniscus and/or cartilage injuries and thereby the risk of increased disability and a subsequent late ACL reconstruction $(\mathrm{n}=$ 55). Otherwise, compensation was rejected if the delay was assessed to be in accordance with accepted medical practice $(n=65)$; for example, if the patient was offered a follow-up appointment at a clinic and did not attend or if the surgery was planned and then delayed due to long waiting lists at the treating clinic that were adjudged to be reasonable and did not impose an increased risk on the patient.

The most commonly accepted claim for nerve injuries was injuries to the infrapatellar nerve or saphenous nerve, resulting in sensory loss in the lower leg $(n=30)$. Sensory loss limited to the area around the scars was not accepted $(n=13)$.

Compensation claims due to scar formation were accepted when there was a delay in wound closure leading to larger scars, usually due to superficial infection $(n=16)$. Claims regarding scars of a magnitude that was adjudged to be unavoidable or skin reactions to dressings were rejected $(n=15)$.

Many patients filed claims relating to persistent pain and stiffness. If the pain and stiffness were considered to be due to suboptimal surgery or misplacement of the graft, the claim was accepted and was categorized accordingly. If no obvious reason for pain and stiffness was found, the claim was rejected ( $\mathrm{n}=42)$.

The category of "others" included some rare claims, such as 1 patient on whom surgery was started on the wrong knee and 1 patient where the ACL was found to be intact at the time of surgery. 1 patient had a serious injury to the popliteal artery and was transferred to an emergency hospital to undergo vascular repair while another patient had vocal cord paralysis due to general anesthesia.

176 patients, $50 \%$ of the accepted claims, were considered to have increased disability. The median increased disability was generally low, varied by type of injury from $2 \%$ to $4 \%$, and was highest for the subgroup "delay in diagnosis and treatment" (4\%). The highest increased disability compensation $(17 \%)$ was given to a patient with a long delay in diagnosis and with subsequent extensive meniscus and cartilage injuries.

293 patients, $84 \%$ of the accepted claims, were considered to have a prolonged period of recovery. There was large variability in the prolonged period of recovery in all types of patient injury subgroups, with the highest median in the subgroup "delay in diagnosis" (90 days) and the lowest median for the subgroups of "nerve injuries" and "wounds and scars" (0 days).

There was also large inter-individual variation regarding economic compensation, with the highest median compensation in the compartment syndrome group $(€ 6,649)$ and the lowest median compensation in the wound and scars group ( $€$ 1,258) (Table 1).

\section{Discussion}

Most patients in the Swedish healthcare system are insured by the Mutual Insurance Company of Swedish County Councils (LÖF). 13 claims were excluded due to the care provider not being included in the insurance. Doctors in private practice without a care agreement with the county council have taken out patient insurance with other insurance companies.

We found that fewer than $1 \%$ of ACL surgeries had a treatment error that was reported to and deemed valid by LÖF. The results are in accordance with previous studies of patient insurance claims following ACL surgery from other Scandinavian countries with similar insurance systems, reporting a filed claims ratio of $1.3-2.4 \%$ and an accepted claims ratio of $0.5-1.4 \%$ in relation to the total number of surgeries (9-11). Even though ACL surgery can therefore be considered to be a safe procedure (12), our assessment is that it is probable that 
Table 1. Demographics of accepted claims groups categorized according to cause. Values are count or median (range)

\begin{tabular}{|c|c|c|c|c|c|c|c|c|c|}
\hline Type of patient injury & $\begin{array}{l}\text { Number } \\
\text { of ACLR }\end{array}$ & Age & $\begin{array}{l}\text { Sex } \\
M / F\end{array}$ & $\mathrm{n}$ & $\begin{array}{c}\text { Increased } \\
\text { disability (\%) }\end{array}$ & $\mathrm{n}$ & $\begin{array}{l}\text { Days of } \\
\text { prolonged } \\
\text { recovery }\end{array}$ & $\mathrm{n}$ & $\begin{array}{l}\text { Economic } \\
\text { compensation } \\
\text { in euros }\end{array}$ \\
\hline Postoperative septic arthritis $(n=158)$ & 158 & $25(14-59)$ & $103 / 55$ & 87 & $3(1-12)$ & 122 & $60(0-480)$ & 154 & $3,344(474-40,613)$ \\
\hline Suboptimal surgery $(n=67)$ & 67 & $25(16-49)$ & $32 / 35$ & 34 & $2(1-10)$ & 57 & $60(0-300)$ & 62 & $3,024(112-21,875)$ \\
\hline Delay in diagnosis or treatment $(n=55)$ & ) 45 & $21(14-53)$ & $28 / 27$ & 11 & $4(1-17)$ & 47 & $90(0-730)$ & 55 & $1,628(183-21,957)$ \\
\hline Nerve injuries $(n=35)$ & 35 & $24(13-48)$ & $14 / 21$ & 32 & $2(1-5)$ & 41 & $0(0-120)$ & 35 & $2,919(256-12,830)$ \\
\hline Wounds and scars $(n=16)$ & 16 & $22(16-50)$ & $11 / 5$ & 2 & $3(1-4)$ & 15 & $0(0-90)$ & 15 & $1,258(128-10,342)$ \\
\hline Compartment syndrome $(n=4)$ & 4 & $21(18-35)$ & $3 / 1$ & 4 & $3(1-5)$ & 3 & $30(14-180)$ & 4 & $6,649(1,959-10,407)$ \\
\hline Others $(n=17)$ & 17 & $28(14-47)$ & $9 / 8$ & 6 & $2(1-2)$ & 8 & $15(0-270)$ & 17 & $2,766(409-6,507)$ \\
\hline
\end{tabular}

the rate of treatment errors of ACL surgeries is higher than that reported in this study. A considerable degree of underreporting of patient injuries after surgery has previously been described in the Swedish clinical setting regarding hip arthroplasty (13).

It is important to highlight the difference between complications of the ACL injury and treatment errors that merit compensation; for example, a rejected claim was for a young patient who suffered pulmonary embolism 8 weeks after ACL reconstruction that led to death. Swedish ACL surgeons are generally restrictive using thromboprophylaxis only when risk factors are present such as a history of thrombosis, use of oral contraceptives, or prolonged immobilization (14). Thorough assessment by the medical experts at LÖF could not find any medical error and the surgeon's treatment plan was in line with accepted medical practice and therefore the compensation claim was rejected although it was a catastrophic complication.

Postoperative septic arthritis was the most common cause among filed and accepted claims $(\mathrm{n}=158,0.4 \%)$ and compensation was granted in all cases. This is in line with other studies of patient insurance claims following ACL reconstructions, where infection is the primary or secondary cause of accepted claims (9-11). The incidence of septic arthritis after ACL reconstruction varies in the literature, from $0.3 \%$ to $1.8 \%$ (15,16). However, Kraus Schmitz et al. (17), in a study of more than 26,000 ACL reconstructions performed in Sweden between 2006 and 2013, found an incidence of septic arthritis of $1.1 \%$. This indicates that about half of the patients suffering from septic arthritis after ACL reconstruction do not file a compensation claim to LÖF.

Postoperative septic arthritis is associated with prolonged rehabilitation and a poorer outcome (18). In more than half the filed and granted claims regarding postoperative septic arthritis, the patients had an increased permanent disability and the vast majority had a prolonged period of recovery. Moreover, a higher proportion of males filed claims due to postoperative septic arthritis, while sex was more evenly distributed in the other subgroups. This agrees with a previous report which identified male sex as an independent risk factor for septic arthritis (17).

Suboptimal surgery and technical errors were the second most common reasons for accepted claims and granted com- pensation $(0.2 \%, \mathrm{n}=67)$, mostly due to problems with incorrect graft placement $(n=24)$ and graft fixation $(n=24)$. In Denmark and Finland, tunnel malpositioning was the leading cause of accepted and compensated claims following ACL surgery, at $0.4 \%$ and $0.3 \%$ respectively $(\mathbf{1 0 , 1 1 )}$. Randsborg et al. (9) found that $0.1 \%$ of ACL reconstructions in Norway were granted compensation due to an inadequate surgical technique, of which incorrect graft placement was the main cause. As a result, the figures presented in our study agree with previous research from Scandinavian countries.

Tunnel placement, graft fixation methods, and graft selection are all important factors affecting the outcome of ACL surgery (19). Previously, femoral drilling using the transtibial technique was used to a large extent. However, it is associated with vertical and anterior graft placement and an increased risk of a non-anatomic placement (20). The anteromedial technique permits a more anatomic horizontal placement of the femoral tunnel, but may lead to an increased risk of a posterior-wall blowout and it is thus considered more technically demanding (20). Munch et al. (10) found a lower incidence of tunnel malpositioning when the anteromedial technique was used. Views on the most correct position of the graft have changed over time, independent of surgical technique from an isometric position to a more anatomic and lower position in the femur (21). The most common reason for an accepted claim was when a graft was placed high because the surgeon was not updated on the consensus regarding surgical technique. These findings highlight the importance of continuous education. During the studied period, the consensus shifted gradually from transtibial to anteromedial portal drilling, but there is no data relating exactly to the distribution of the 2 techniques in ACLR. In 2019, approximately 90\% of ACL reconstructions in Sweden were performed using the anteromedial technique, while the transtibial method was only used in 6\% (SNKLR; www.aclregister.nu). LÖF's assessment of the medical records and patient insurance claims was based on the current state of knowledge during the time period when the ACL surgery was performed. For this reason, claims regarding the malpositioning of the graft using the transtibial technique were more likely to be rejected during the first part of the studied period. 
Diagnostic errors and treatment delays were other common reasons for filed claims and compensation granted in this study. The initial diagnostic accuracy of ACL rupture is poor and, according to Arastu et al. (22), fewer than a third of patients with an ACL injury receive the correct diagnosis at the primary medical consultation, even though most patients describe a typical injury mechanism, present with characteristic symptoms, and seek medical consultation within 1 week. Olsson et al. (23) studied more than 1,100 patients with traumatic knee distortion, showing that at least half of all knee injuries with hemarthrosis had an underlying ACL tear. Furthermore, a delay in diagnosis is associated with an increased risk of secondary injury to the knee. Cristiani et al. (24) found an increased risk of cartilage and medial meniscus injuries if ACL reconstruction was delayed for more than 12 months, and an increased risk of abnormal pre-reconstruction instability and reduced odds of medial meniscus repair if ACL surgery was delayed for more than 6 months. It is therefore important that healthcare providers are observant when it comes to patients with immediate knee pain and effusion after an acute knee injury and that further investigation with MRI or referral to a specialist clinic is made.

The limitations of this study are its retrospective design and the fact that it reflects only patient-reported claims. As a result, the actual number of patient injuries and treatment errors following ACL reconstructions in Sweden cannot be assessed in this report. We found that ACL-related treatment errors and patient injuries are rare but probably largely underreported. It is important that healthcare providers secure an active followup of ACL-injured patients and, in the case of adverse events, inform them of the opportunity to file a claim.

In conclusion, there are different reasons for accepted claims, which represent different treatment errors that can be avoided. For the surgeon, aw areness of complications remains the prime prevention and wise surgeons take note.

The authors would like to thank Pelle Gustafson, chief medical officer at LÖF, for his support in performing this study.

OO built the database based on LÖF and Xbase, and sorted and analyzed data. OO and DR wrote the first draft of the manuscript together and participated in the revision of the manuscript. MW, KE, and BB participated in analysis of data and revision of the manuscript. AS, the initiator of the project, participated in analysis of data and revision of the manuscript.

Acta thanks Kim Lyngby Mikkelsen and Per-Henrik Randsborg for help with peer review of this study.

1. SR-PSA. SverigesRiksdag. Svensk författningssamling, Patientsäkerhetslag(2010:659). [The Swedish Parliament, Patient Safety Act], 2017:786.

2. SR-PIA. SverigesRiksdag. Svensk författningssamling, Patientskadelag(1996:799) [The Swedish Parliament, Patient Injury Act], 2017:43.
3. Nordenvall R, Bahmanyar S, Adami J, Stenros C, Wredmark T, Fellander-Tsai L. A population-based nationwide study of cruciate ligament injury in Sweden, 2001-2009: incidence, treatment, and sex differences. Am J Sports Med 2012; 40(8): 1808-13.

4. Granan L P, Forssblad M, Lind M, Engebretsen L. The Scandinavian ACL registries 2004-2007: baseline epidemiology. Acta Orthop 2009; 80(5): 563-7. doi: 10.3109/17453670903350107.

5. Ahlden M, Samuelsson K, Sernert N, Forssblad M, Karlsson J, Kartus J. The Swedish National Anterior Cruciate Ligament Register: a report on baseline variables and outcomes of surgery for almost 18,000 patients. Am J Sports Med 2012; 40(10): 2230-5.

6. Kraus Schmitz J, Lindgren V, Janarv P M, Forssblad M, Stalman A. Deep venous thrombosis and pulmonary embolism after anterior cruciate ligament reconstruction. Bone Joint J 2019; 101-B(1): 34-40.

7. Jonsson P M, Tomson G, Raf L. Reducing error, improving safety: no fault compensation protects patients in Nordic countries. BMJ 2000; 321(7259): 506.

8. Pukk-Harenstam K, Ask J, Brommels M, Thor J, Penaloza R V, Gaffney F A. Analysis of 23364 patient-generated, physician-reviewed malpractice claims from a non-tort, blame-free, national patient insurance system: lessons learned from Sweden. Postgrad Med J 2009; 85(1000): 69-73.

9. Randsborg P H, Bukholm I R K, Jakobsen R B. Compensation after treatment for anterior cruciate ligament injuries: a review of compensation claims in Norway from 2005 to 2015. Knee Surg Sports Traumatol Arthrosc 2018; 26(2): 628-33.

10. Munch D R K, Hansen T I, Mikkelsen K L, Krogsgaard M R. Complications and technical failures are rare in knee ligament reconstruction: analyses based on 31,326 reconstructions during 10 years in Denmark. Knee Surg Sports Traumatol Arthrosc 2019; 27(8): 2672-9.

11. Nyrhinen K M, Bister V, Helkamaa T, Schlenzka A, Sandelin H, Sandelin $\mathbf{J}$, et al. Anterior cruciate ligament reconstruction-related patient injuries: a nationwide registry study in Finland. Acta Orthop 2019; 90(6): 596-601.

12. Mohtadi N, Chan D, Barber R, Paolucci E O. Reruptures, reinjuries, and revisions at a minimum 2-year follow-up: a randomized clinical trial comparing 3 graft types for ACL reconstruction. Clin J Sport Med 2016; 26(2): 96-107.

13. Kasina P, Enocson A, Lindgren V, Lapidus L J. Patient claims in prosthetic hip infections: a comparison of nationwide incidence in Sweden and patient insurance data. Acta Orthop 2018; 89(4): 394-8.

14. Ekdahl V, Stålman A, Forssblad M, Samuelsson K, Edman G, Kraus Schmitz J. There is no general use of thromboprophylaxis and prolonged antibiotic prophylaxis in anterior cruciate ligament reconstruction: a nation-wide survey of ACL surgeons in Sweden. Knee Surg Sports Traumatol Arthrosc 2020; 28(8): 2535-42.

15. Torres-Claramunt R, Pelfort X, Erquicia J, Gil-Gonzalez S, Gelber P E, Puig L, et al. Knee joint infection after ACL reconstruction: prevalence, management and functional outcomes. Knee Surg Sports Traumatol Arthrosc 2013; 21(12): 2844-9.

16. Waterman B R, Arroyo W, Cotter E J, Zacchilli M A, Garcia E J, Owens B D. Septic arthritis after anterior cruciate ligament reconstruction: clinical and functional outcomes based on graft retention or removal. Orthop J Sports Med 2018; 6(3): 2325967118758626.

17. Kraus Schmitz J, Lindgren V, Edman G, Janarv P M, Forssblad M, Stålman A. Risk factors for septic arthritis after anterior cruciate ligament reconstruction: a nationwide analysis of 26,014 ACL reconstructions. Am J Sports Med 2021; 49(7): 1769-76.

18. Kursumovic K, Charalambous C P. Graft salvage following infected anterior cruciate ligament reconstruction: a systematic review and metaanalysis. Bone Joint J 2016; 98-B(5): 608-15.

19. Markatos K, Kaseta M K, Lallos S N, Korres D S, Efstathopoulos N. The anatomy of the ACL and its importance in ACL reconstruction. Eur $\mathrm{J}$ Orthop Surg Traumatol 2013; 23(7): 747-52. 
20. Robin B N, Jani S S, Marvil S C, Reid J B, Schillhammer C K, Lubowitz J H. Advantages and disadvantages of transtibial, anteromedial portal, and outside-in femoral tunnel drilling in single-bundle anterior cruciate ligament reconstruction: a systematic review. Arthroscopy 2015; 31(7): 1412-17.

21. Jaecker V, Zapf T, Naendrup J H, Pfeiffer T, Kanakamedala A C, Wafaisade A, et al. High non-anatomic tunnel position rates in ACL reconstruction failure using both transtibial and anteromedial tunnel drilling techniques. Arch Orthop Trauma Surg 2017; 137(9): 1293-9.

22. Arastu M H, Grange S, Twyman R. Prevalence and consequences of delayed diagnosis of anterior cruciate ligament ruptures. Knee Surg
Sports Traumatol Arthrosc 2015; 23(4): 1201-5. doi: 10.1007/s00167014-2947-z. Epub 2014 Mar 27. PMID: 24671385.

23. Olsson O, Isacsson A, Englund M, Frobell R B. Epidemiology of intraand peri-articular structural injuries in traumatic knee joint hemarthrosis: data from 1145 consecutive knees with subacute MRI. Osteoarthritis Cartilage 2016; 24(11): 1890-7. doi: 10.1016/j.joca.2016.06.006.

24. Cristiani R, Janarv P M, Engström B, Edman G, Forssblad M, Stålman A. Delayed anterior cruciate ligament reconstruction increases the risk of abnormal pre-reconstruction laxity, cartilage, and medial meniscus injuries. Arthroscopy 2021; 37(4): 1214-20. doi: 10.1016/j. arthro.2020.11.030. Epub 2020 Nov 23. PMID: 33242630. 